\title{
On the correlation between drug-resistant pattern of HIV-I protease inhibitors and binding free energy and structural changes Kitiyaporn Wittayanarakul ${ }^{* 1}$, Supot Hannongbua ${ }^{1}$ and Michael Feig ${ }^{2}$
}

\author{
Address: ${ }^{1}$ Departments of Chemistry, Faculty Of Science, Chulalongkorn University, Bangkok, Thailand and ${ }^{2}$ Department of Biochemistry and \\ Molecular Biology and Department Of Chemistry, Michigan State University, East Lansing, MI, USA \\ Email: Kitiyaporn Wittayanarakul* - mameow50@yahoo.com \\ * Corresponding author
}

from BioSysBio 2007: Systems Biology, Bioinformatics and Synthetic Biology Manchester, UK. II-13 January 2007

Published: 8 May 2007

BMC Systems Biology 2007, I(Suppl I):P58 doi:I0.I I86/I752-0509-I-SI-P58

This abstract is available from: http://www.biomedcentral.com/I752-0509/I?issue=SI

(C) 2007 Wittayanarakul et al; licensee BioMed Central Ltd.

\section{Introduction}

Protease inhibitor (PR) resistance remains the major limiting in the treatment of HIV infection. Understanding source of mutation at molecular level is a key of success in research and drug discovery. The present studies aim to examine relation between clinical data of drug resistance and the molecular properties obtained from molecular dynamics simulations (MD).

\section{Materials and methods}

MD simulations of 6 FDA-approved drugs, which are Lopinavir (LPV), Ritonavir (RTV), Saquinavir (SQV), Indinavir (IDV), Amprenavir (APV), and Nelfinavir (NFV), were performed using AMBER 8. The total inhibitorenzyme binding free energy $\left(\Delta G_{\text {total }}\right)$ including entropic contributions of 6 complexes was estimated based on $\mathrm{MM}-\mathrm{PB}(\mathrm{GB}) \mathrm{SA}$ approach. The decomposition free energy $\left(\Delta G_{D C}\right)$, representing interaction between inhibitor and each residue, was calculated and used as the criteria for the mutation prediction.

\section{Results}

In comparison to the expermental binding free energy, the $\Delta G_{\text {total }}$ for the 6 complexes yields the standard deviation of $\pm 2.29 \mathrm{kcal} / \mathrm{mol}$, indicating reliability of the method used. To seek for the correlation between resistance according to the clinical data and the molecular properties according to the MD results, the $\Delta G_{D C}$ and the structural changes (in term of the root mean square displacement, $R M S D$, of each residue) were evaluated. For simplicity, the notations $\mathrm{F}$ (favourable), U (unfavourable) and S (structure) were, then, used to represent the residue which gives the $\Delta G_{D C}$ lower than $-0.5 \mathrm{Kcal} / \mathrm{mol}$, the $\Delta G_{D C}$ higher than $0.5 \mathrm{kcal} /$ mol and the RMSD higher than $2.0 \AA$, respectively. In addition, the notation I (indirect) was used to represent the residue which locates close to or between the two residues which have $\mathrm{F}, \mathrm{U}$ and/or $\mathrm{S}$ character, i.e., mutation takes place due to the influence of the $\mathrm{F}, \mathrm{U}$ and/or $\mathrm{S}$ residues. Table 1 contains the mutated residues which correlated with the level of resistance according to the clinical data [1] for 6 drugs. The F, U, S and I characteristic of each residue extracted from the MD trajectories for the $6 \mathrm{com}$ plexes were accordingly given. Subscripts $\mathrm{a}$ and $\mathrm{b}$ indicate its location in chain A and chain B of the HIV-1 PR, respectively. It can be clearly seen that most of the high-level resistance (very dark-blue) takes place at the residues which bind strongly to the inhibitor $\left(\mathrm{F}, \Delta G_{D C}<-0.5 \mathrm{kcal} /\right.$ $\mathrm{mol}$ ) and/or residues which have high RMSD (S, RMSD > $2.0 \AA$ A . The data shows also that most of the indirect effect, I, effects lead to the low-level resistance (dark blue) and contribute to resistance (light blue). Figure 1 displays location of the residues for the LPV/enzyme complex with different levels of resistances; green for $\mathrm{F}$, light-blue for $\mathrm{U}$, brown for $\mathrm{S}$. The pink and blue CPK represent the mutated residues which are intermediate and contributes to resistance level, respectively. It appears that the mutated residues due to the indirect effect are surrounded by those which have $\mathrm{F}$, $\mathrm{U}$ and/or $\mathrm{S}$ characters. 


\section{Conclusion}

Direct correlation between the experimental drug resistance and the calculated binding free energies obtained from the MM-PB(GB)SA as well as the structural changes was observed. Examination was performed for the 6 FDAapproval inhibitors.

See Table $1 \&$ Figure 1 at http://openwetware.org/wiki/ BioSysBio:abstracts/2007/Kitiyaporn_Wittayanarakul

\section{References}

I. Richard T, Jonathan M: Drug Resistance Mutations. Special Contribution 2002, 1 0:21-25.

Publish with Bio Med Central and every scientist can read your work free of charge

"BioMed Central will be the most significant development for disseminating the results of biomedical research in our lifetime. " Sir Paul Nurse, Cancer Research UK

Your research papers will be:

- available free of charge to the entire biomedical community

- peer reviewed and published immediately upon acceptance

- cited in PubMed and archived on PubMed Central

- yours - you keep the copyright

Submit your manuscript here:

http://www.biomedcentral.com/info/publishing_adv.asp 